Cotton, P.B., Rosenberg, M.T., Waldram, R.P.L. \& Axon, A.T.R. (1973) Early endoscopy of oesophagus, stomach and duodenal bulb in patients with haematemesis and melaena. British Medical Journal, 2, 505.

Forbes, C.D., Barr, R.D., Prentice, C.R.M. \& Douglas, A.S. (1973) Gastrointestinal bleeding in haemophilia. Quarterly Journal of Medicine, N.S., XLII, 503.

Martel, W., Scholtens, P.A. \& Lim, L.W. (1969) Tubeless hypotonic duodenography: Technique value and limitations. American Journal of Roentgenology, 107, 119.
SHERLOCK, S. (1968) Diseases of the Liver and Biliary System, 4th edition, 758-766. Blackwell Scientific Publications, Oxford.

Stuart, J., Davies, S.H., Cumming, R.A., Girdwood, R.H. \& DARG, A. (1966) Haemorrhagic episodes in haemophilia-a 5 year prospective study. British Medical Journal, 2, 1624.

Wilkinson, J.F., Nour-Eldin, F., IsRaels, M.C.G. \& BARRETT, K.E. (1961) Haemophilia syndromes. A survey of 267 patients. Lancet, ii, 947.

\title{
Pancreatitis and hyperparathyroidism
}

\author{
R. D. Rosin \\ M.B., B.S., F.R.C.S.(Ed), F.R.C.S. \\ Professorial Surgical Unit, Westminster Hospital, London
}

\begin{abstract}
Summary
Three patients with acute pancreatitis were found also to have hyperparathyroidism, two of them also formed pancreatic cysts. There appears to be more than an incidental relationship between the two diseases. The importance of serum calcium estimations in patients with pancreatitis is stressed. Theories as to why these diseases co-exist are reviewed.
\end{abstract}

\section{Introduction}

Hyperparathyroidism is one of the hormonal conditions that may be an aetiological factor in pancreatitis. However, the precise frequency with which pancreatitis occurs in association with hyperparathyroidism is not known. Mixter, Keynes and Cope (1962) found sixty-two cases of these diseases co-existing and reported that pancreatitis occurred in eleven out of 155 patients with hyperparathyroidism. It appears that either the coexistence of these two diseases is not as common in the United Kingdom as in the United States of America, or that pancreatitis is not investigated so thoroughly to exclude hyperparathyroidism.

\section{Case 1}

A 72-year-old man was admitted in December 1971 to Sutton Hospital as an emergency with a sudden onset of colicky abdominal pain which did not radiate to his back. He gave no history of indigestion, vomiting, change of bowel habit or change in colour of his stools or urine. He was known to have chronic bronchitis and emphysema and cardiographic evidence of ischaemic heart disease. He smoked twenty cigarettes per day and admitted to a moderate alcohol intake.

On examination he was an ill looking man with a pulse rate of $92 / \mathrm{min}$. His blood pressure was $200 / 110$ $\mathrm{mmHg}$. He was apyrexial, and his tongue was dry and coated. The thyroid gland was not enlarged. There was guarding and tenderness across the upper abdomen. The results of the main investigations performed were: haemoglobin $11.9 \%$; white blood count $15.000 \mathrm{~mm}^{3}$; serum amylase 3700 Somogyi units; urea and electrolytes were within normal limits. Radiological examination showed a calcified pleural plaque on the left side with a small pneumothorax. An X-ray of the abdomen was normal, and there were no pancreatic calculi.

A diagnosis of pancreatitis was made, and the patient was treated with intravenous fluids, papaveretum $20 \mathrm{mg}$, ampicillin $500 \mathrm{mg}$, and trasylol 25,000 u 6 hourly, the latter administered via the infusion and continued for $\mathbf{8}$ days. On the following day his condition was unchanged, although he felt more comfortable. Bruising was present in his left flank (Grey Turner's sign). The serum calcium was measured and found to be $13.4 \mathrm{mg} / 100 \mathrm{ml}$ (normal range $8 \cdot 5-10.5 \mathrm{mg} / 100 \mathrm{ml}$ ). Forty-eight hours after admission he became shocked and had an irregular tachycardia of $116 / \mathrm{min}$ with profuse sweating. He was digitalized and the diagnosis of acute pancreatitis was confirmed by a peritoneal aspiration which showed typical blood-stained plum-coloured fluid. 


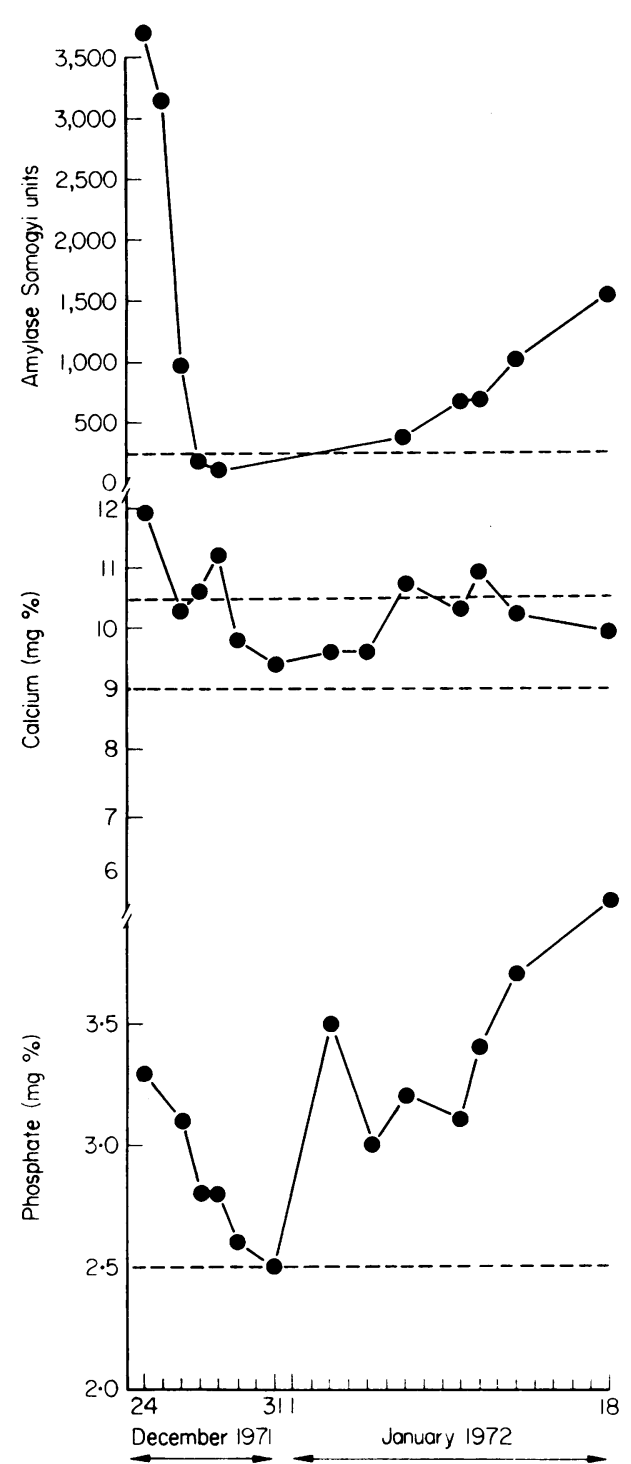

FIG. 1. Biochemical results of case 1. Top, amylase; centre, calcium; bottom, phosphate.

Because of the hypercalcaemia found initially further estimations of serum calcium were made (Fig. 1), and an additional diagnosis of hyperparathyroidism was considered. Subsequently, radiological studies were performed to try to substantiate this diagnosis, but a skeletal survey and intravenous pyelogram were normal. A cholecystogram did not show any radio-opaque gall stones but the gall bladder failed to concentrate the contrast medium.

Eighteen days after admission he complained of episodic peri-umbilical pain. On examination his abdomen was distended and the bowel sounds were $\frac{\Phi}{\overparen{D}}$ absent. He was dehydrated but not shocked. A diagnosis of a pseudo-pancreatic cyst was made and $\stackrel{.}{\Rightarrow}$ he was treated with naso-gastric suction and intravenous fluids. Eight days later he was much improved $\overline{0}$ and a barium meal was performed which showed a $\overline{ }$ small hiatus hernia present with gastro-oesophageal $\overline{\bar{\sigma}}$. reflux. The duodenal loop was stretched, and the $\overparen{\varnothing}$ greater curve border of the stomach in the pyloric antral region was indented. Two days later he became breathless, and suddenly died.

Post-mortem examination showed the primary $\overrightarrow{\vec{\omega}}$ cause of death was pulmonary oedema secondary to $\stackrel{\omega}{\sigma}$ hypertensive heart failure. The peritoneal cavity was $\overline{0}$ heavily flecked with necrotic fatty material, espec- 3 . ially in the lesser sac. The pancreas was grey and of necrotic with virtually no normal pancreatic tissue $\stackrel{N}{\sigma}$ left, and there was a cyst anterior to it containing $\odot$ two litres of clear fluid. A large parathyroid tumour io weighing $6.3 \mathrm{~g}(3 \mathrm{~cm} \times 2.5 \mathrm{~cm})$ was discovered in the right lower parathyroid gland. Histology proved it to be a typical parathyroid adenoma.

\section{Case 2}

A 17-year-old male was admitted to West Kent General Hospital in October 1970 as an emergeney $\overrightarrow{0}$ with a history of ten days' central abdominal paim constipation, and intermittent vomiting. On examina tion there was slight tenderness over the uppeat abdomen, and he was pyrexial. On the fifth day after his admission he was noted to be slightly jaundiced. Investigations performed showed that the serum amylase value was 217 Somogyi units, and the serum $\stackrel{\odot}{\complement}$ bilirubin was $1.8 \mathrm{mg} / 100 \mathrm{ml}$. The white blood count $\overrightarrow{\vec{B}}$ was $14,000 / \mathrm{mm}^{3}$ ( $94 \%$ polymorphs), and the ESR $25 \frac{3}{3}$ $\mathrm{mm} / \mathrm{hr}$. Examination of a MSU specimen was sterile, and there was no bile in the urine. The Widal test was within normal limits. A provisional diagnosis of acute pancreatitis was made, the normal serum 3 . amylase value being explained by the delay in performing the test in relation to the patient's length of history. The patient become apyrexial, and $\delta$ was discharged twelve days after admission. A $₹$ cholecystogram performed as an outpatient showed 의 poor concentration of the contrast medium in the $D$ gall bladder.

Two months after discharge the patient was readmitted with abdominal pain maximal in the left $\%$ loin, and radiating to the tip of the left shoulder. $)$ On examination he was pyrexial and a firm mass $\underset{\omega}{N}$ was palpable in the left side of the epigastrium. An intravenous pyrelogram was performed and showedo poor filling of the upper calyces on the left side. $\overline{\mathbb{D}}$ Barium meal showed a soft tissue shadow causing $\stackrel{\infty}{+}$ extrinsic pressure on the lesser curvature of the 70 stomach. A diagnosis of a pancreatic cyst was made, $\frac{\vec{D}}{\mathbb{D}}$ 
and the patient was transferred to Westminister Hospital 4 weeks later.

On admission he complained of episodic abdominal pain, had lost 2 stone in weight, and his bowel function and micturition were normal. He gave a history of mumps 7 years previously but he was a non-smoker and had no history of excess alcoholic intake. On examination his general condition was good, and he was not jaundiced. There was no palpable abnormality in the neck but on abdominal examination there was a mass in the epigastrium. An X-ray of the chest was normal, and a repeat barium meal examination showed a soft tissue shadow displacing the stomach forwards. A skeletal survey was normal and the only abnormal biochemical estimation was of a persistently elevated serum calcium (Fig. 2). The hypercalcaemia was not suppressed by cortisone, being consistent with a diagnosis of hyperparathyroidism.

Approximately 1 month after admission a laparotomy was undertaken, and a pseudopancreatic cyst was discovered containing $850 \mathrm{ml}$ of fluid. Cystogastrostomy was performed. After a further 3 weeks a surgical exploration of the neck was undertaken. The left superior pole of the thyroid was ligated and divided, and a left upper parathyroidectomy was performed. The other parathyroid glands were identified and considered to be normal. Histological examination of the gland removed confirmed that it was a parathyroid tumour and that there was no evidence of malignancy.

The patient made a good post-operative recovery although initially his serum calcium remained elevated (Fig. 2). When seen as an outpatient 6 weeks after parathyroidectomy he was very well and had gained a stone in weight. The serum calcium and phosphate values were now within normal limits; however, his ESR was raised $(33 \mathrm{~mm} / \mathrm{hr})$ and his haemoglobin was $12.6 \mathrm{~g} / 100 \mathrm{ml}$. A right renal arteriogram, aortogram, and bilateral thyroid arteriograms were all normal at this time. Subsequently his serum calcium and phosphate have remained within normal limits.

\section{Case 3}

A woman aged 38 presented in March 1966 as an emergency to the Manchester Royal Infirmary with pain in the right renal angle, vomiting, nausea, anorexia, lassitude and headaches. She gave a history of recurrent symptoms localized to her left kidney since pregnancy 3 years previously. Shortly before admission she complained that her urine volume had diminished and there was possibly some blood in it. On examination she looked ill, was clinically anaemic and dehydrated. Her temperature was $100 \cdot 8^{\circ} \mathrm{F}$, and her pulse rate was $88 / \mathrm{min}$. There was marked tenderness in the right renal angle with guarding. The

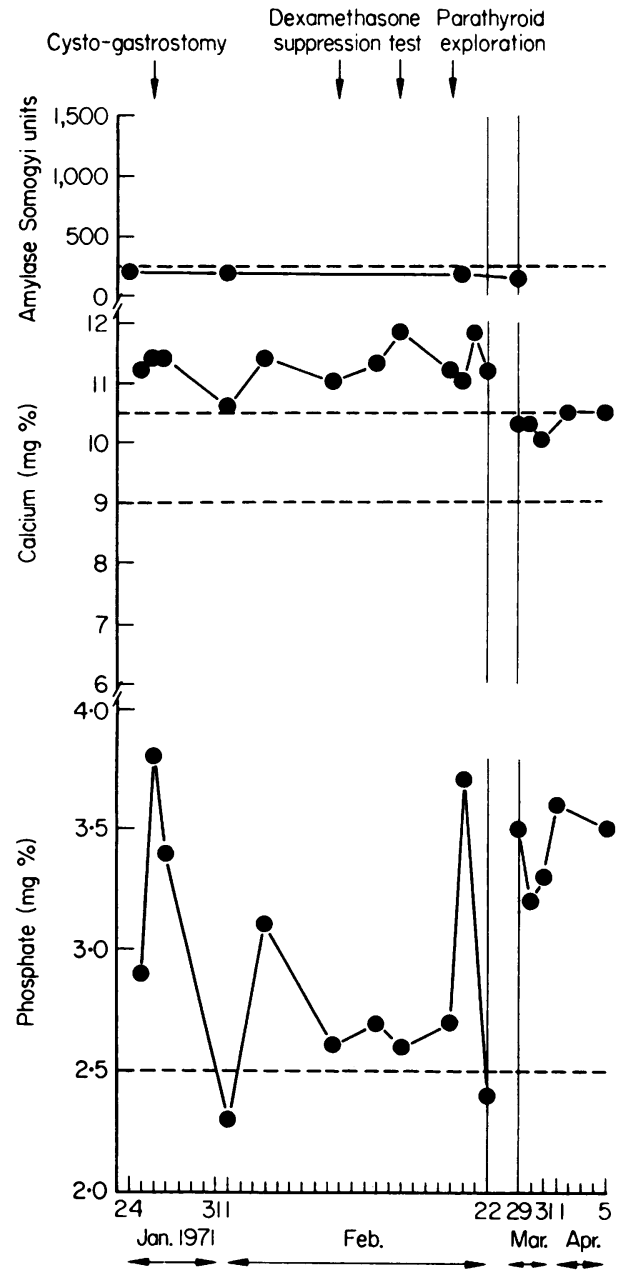

Fig. 2. Biochemical results of case 2. Top, amylase; centre, calcium; bottom, phosphate.

bladder was not palpable, and rectal examination was normal.

A provisional diagnosis of right pyelonephritis was made. Investigations on admission showed a haemoglobin of $13.4 \mathrm{~g} / 100 \mathrm{ml}$, and a white blood count of $5400 / \mathrm{mm}^{3}$. The blood urea was $100 \mathrm{mg} / 100$ $\mathrm{ml}$ but the electrolytes were normal. The patient was treated with pethidine and ampicillin $250 \mathrm{mg}$ six hourly. In spite of some improvement in her symptoms she remained pyrexial and developed rigors. Intravenous pyelography showed a calculus in the the right ureter with an associated dilatation of the ureter and renal pelvis. No function was seen in the left kidney although a calculus was seen in the line of the left ureter. A diagnosis of bilateral obstructive nephropathy was made.

Two-and-a-half weeks after admission surgical 


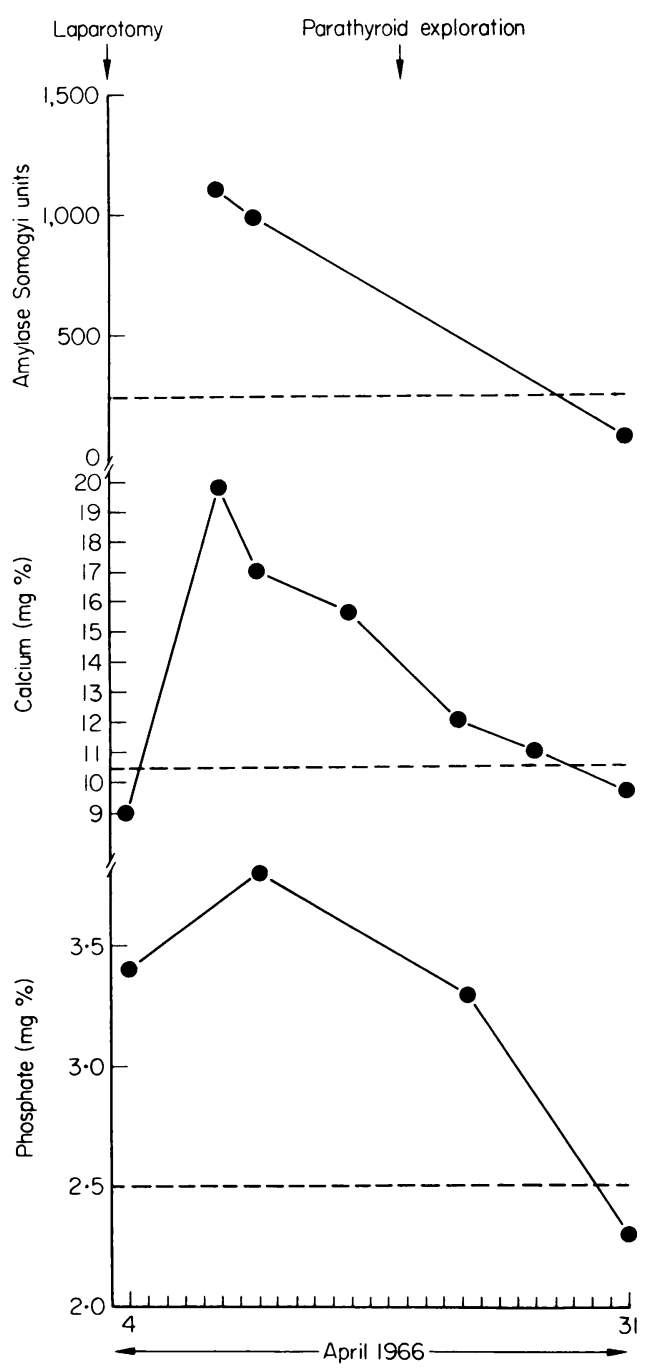

FIG. 3. Biochemical results of case 3. Top, amylase; centre, calcium; bottom, phosphate.

exploration of both renal areas was undertaken. The right perinephric tissues were inflamed and oedematous and a stone was removed from the right ureter. There were similar findings on the left side and a ureteric stone was also removed.

The patient made a very slow post-operative recovery, and on the sixth post-operative day complained of upper abdominal pain and distension. A laparotomy was performed at which she was found to have an acute pancreatitis, and a subsequent serum amylase estimation was 1100 Somogyi units. The initial serum calcium measurement at this time was $9 \mathrm{mg} / 100 \mathrm{ml}$, however, 1 week later it had risen to $19.7 \mathrm{mg} / 100 \mathrm{mk}$, and remained elevated (Fig. 3).
A diagnosis of primary hyperparathyroidism was气 then made to account for the severe hypercalcaemia $\frac{3}{\mathrm{D}}$ renal calculi and associated pancreatitis.

A subsequent surgical exploration of the neck was. performed and a very large parathyroid adenomas weighing $10 \mathrm{~g}$ was removed from the site of the lefto upper parathyroid gland. The diagnosis was confirmed histologically and no evidence of malignancy $\overline{\bar{n}}$. was detected. The post-operative serum calcium $\bar{D}$ values are shown in Fig. 3, and the patient made an uneventful recovery. When last seen as an outpatiente she remained well but had a slightly elevated serum $\overrightarrow{0}$ calcium value $(11 \cdot 1 \mathrm{mg} / 100 \mathrm{ml})$.

\section{Discussion}

Pancreatitis may be a diagnostic clue to hyper-i parathyroidism (Cope et al., 1957). In the cases reported in this paper the raised serum calcium levels in conjunction with a diagnosis of acuteio pancreatitis supported this association. However $\mathcal{O}^{\mathcal{O}}$ until 1956, only a few isolated cases had been? reported (Dawson and Struthers, 1923; Smith and ${ }^{-}$ Cooke, 1940; Rogers, 1946; Martin and Conseka, 1947; Page, 1954). Erdheim (1903) probably described the first association when he reported a patient with multiple endocrine tumours including $\mathrm{a}_{-}$ parathyroid adenoma, who was found at post mortem to have a necrotic pancreas.

Since then many cases have been described, mos in American publications, the largest series bys Mixter et al. (1962). They reported eleven cases of pancreatitis out of 155 cases of hyperparathyroidism in Massachusetts General Hospital between 1950 and $\frac{\mathscr{Q}}{\mathscr{\Phi}}$ 1962 ; an incidence of $7 \%$. In a review of previous $\overrightarrow{\vec{F}}$ publications they discovered fifty-one other cases, $\Xi$ making a total of sixty-two. Only seventeen of these? had been reported before 1956. In thirty of theo entire group it was the diagnosis of pancreatitis which led to the discovery of hyperparathyroidism 3 . In that review, Mixter estimated that pancreatitiso occurred in between $7 \%$ and $10 \%$ of patients with hyperparathyroidism. Anglem (1966) gives theô incidence as $11.5 \%$. A review of twenty-seven cases of 2 pancreatitis with hyperparathyroidism together with을 one of their own was recorded by Turchi et al. (1962). $>$ Jawaheer (1963) similarly collected twenty-six cases을. of associated pancreatitis and hyperparathyroidism $N$ and added one further case. Other single case reports. have appeared sporadically (Keynes, 1962; Steyn, $\mathcal{N}^{\circ}$ Duncan and Logie, 1966; Kelly and Falor, 1968; స్ల Battersby, Burnett and Winch, 1969; Ory, HiseyO and Redmond, 1970; Ballon, Cohen and Strasberg 1972; Lejeune et al., 1972). Interestingly, Trapnell/ (1966) reported only one case of co-existing pan-? creatitis and hyperparathyroidism in 403 cases of 0 pancreatitis reviewed. Dent (1962) reported four $\frac{\overrightarrow{\mathrm{D}}}{\mathrm{D}}$ 
cases of pancreatitis in eighty cases of hyperparathyroidism, and Aldis (1961) mentions eight cases of the two diseases co-existing.

This suggests that the incidence of these two diseases co-existing in this country and Europe appears to be far less than in the United States of America. Twenty-six hospitals have been contacted in the United Kingdom and, surprisingly, only nine cases (of which three are reported here) have been discovered between 1962 and 1972, over and above those single cases already reported. Seven hospitals failed to acknowledge the communication. During this time approximately 1000 cases of hyperparathyroidism were seen in the other nineteen hospitals contacted, giving an approximate incidence of less than $1 \%$. This is significantly lower than the $7-12 \%$ quoted in the American literature.

Most of the surgeons and physicians contacted reported the increased incidence of peptic ulcers and the Zollinger-Ellison syndrome with hyperparathyroidism, but not of pancreatitis (Rogers et al., 1947; Morrison, 1973; McGeown, 1973; Green, 1972; Taylor, 1972; Howat, 1972; Watson, 1972). Fink and Finrock (1961) stated that $66 \%$ of cases of hyperparathyroidism had gastro-intestinal symptoms but there was no evidence of pancreatitis. Lejeune et al. (1972) gave an incidence of about $5 \%$ of cases of pancreatitis in their series of thirty-eight cases of hyperparathyroidism, and Schmidt and Creutzfeldt (1970), reviewing 370 cases of hyperparathyroidism in Europe, found an incidence of $6.5 \%$ with co-existing pancreatitis.

In the group of sixty-two collected cases reported by Mixter et al. (1962), of those patients whose sex was recorded, thirty-two were male and twenty-five female, whereas in hyperparathyroidism as a whole, females are more numerous. They also stated that in all types of pancreatitis female patients predominated. Two of the patients described here were male, and of the other six patients found in the hospitals contacted, four were male.

Both Cope et al. (1957) and Meltzer et al. (1962) have pointed out that the aetiological association between hyperparathyroidism and pancreatitis is well established and that patients with pancreatitis must be studied appropriately in order to exclude hyperparathyroidism, even when the more common manifestations of this disease are absent. Cope reports that the incidence of hyperparathyroidism and pancreatitis co-existing varies directly with the diligence of the investigators. The mechanism of this association is not established. Many different theories have been proposed, but none can fully explain the interrelationship between these two diseases.

The mechanism of pancreatitis itself has never been fully elucidated. The following are the main theories
(Bockus, 1969): blockage of the ampulla of Vater, leading to reflux of bile into the pancreatic duct causing an increase in the ductal pressure which in turn leads to rupture of acini. Another theory is that the pancreatic duct becomes blocked by epithelial metaplasia. A virus (because of the association of mumps with acute pancreatitis), reflux of the duodenal contents of the pancreatic duct, and thrombosis in the pancreatic vessels leading to infarction of the pancreas with resulting release of the pancreatic juices (Hueper, 1927), have all been postulated as possible causes. The acute pancreatitis in some instances was thought to be secondary to stone formation in the pancreatic ductal system or interstitial pancreatic calcification as a result of hypercalcaemia and/or alkaline pancreatic secretion created by hyperparathyroidism. In Mixter's series of sixtytwo cases, $81 \%$ had calcified deposits in the pancreas.

Calcium salts in the presence of hypercalcaemia are liable to be precipitated as calcium phosphate in ducts or cells in which there is an alkaline secretion of medium (Hoar and Gorlin, 1958); a combination of circumstances believed to be the explanation of the calcification which occurs in the pancreas, prostate and possibly the kidney with hyperparathyroidism (Pyrah, Hodgkinson and Anderson, 1966). Oliver (1939) reported two cases of hyperparathyroidism with widespread calcification in other organs but without calcification in the pancreas. However, pancreatitis in the absence of calculi or pancreatic calcinosis has been recorded in patients with hyperparathyroidism.

Sinclair (1965) emphasized that the concentration of calcium in the pancreatic juice normally approximates to that of the diffusible calcium in the plasma, When this level is high, as in hyperparathyroidism, the excess of calcium may accelerate the conversion of inactive trypsin into trypsinogen, a reaction which is dependent upon a suitable concentration of calcium ions (Haverback et al., 1960); the free trypsin so formed may initiate an attack of pancreatitis.

Kelly (1968), on the basis of his experimental study on rats, calculated that a time relationship existed between hyperparathyroidism and pancreatitis through the following sequence of events; hyperparathyroidism, elevated serum calcium, increased pancreatic juice calcium, accelerated calciumdependent conversion of trypsinogen to trypsin, and pancreatitis.

That hypercalcaemia per se, rather than parathyroid hormone or calcific ductal obstruction, may be the common aetiological source of pancreatitis is suggested by Meltzer et al. (1962). If it were due to parathyroid hormone alone, then pancreatitis would only occur together with hyperparathyroidism. They describe a case of acute necrosis of the pancreas 
in association with the hypercalcaemia of multiple myeloma without pancreatic calcification. Aldis (1961) has described a patient with hypercalcaemia $(17 \mathrm{mg} / 100 \mathrm{ml})$ who developed fatal pancreatitis. At post-mortem, the cause of her hypercalcaemia was found to be multiple myeloma. Leeson and Fourman (1966) also incriminate vitamin D poisoning in a woman who was hypoparathyroid following two thyroidectomies, which led to pancreatitis; they believed the pancreatitis was due to the hypercalcaemia.

If hypercalcaemia per se was the sole cause for pancreatitis, then all conditions of hypercalcaemia leading to an increased serum calcium should also have co-existent pancreatitis. This is, of course, not the case. Indeed, Meltzer has pointed out the need for a factor other than hypercalcaemia since he and his colleagues performed post-mortem examinations on twenty-one patients with hypercalcaemia without any evidence of pancreatitis.

Certain vascular abnormalities are believed to be of aetiological importance in some cases of pancreatic damage found in patients with arteriosclerosis, periarteritis nodosa and arterial embolism. In the case of pancreatitis complicating hyperparathyroidism reported by Henriksson (1960), similar thrombi were found in the vessels of the pancreas and in those of the kidney. Jackson (1958) also believes that when the two conditions co-exist, the pancreatitis is secondary to primary hyperparathyroidism. He described a family in which seven of the members had hereditary hyperparathyroidism of whom two developed recurrent pancreatitis. Their symptoms were relieved by excision of the parathyroid tumours. However, Plough and Kyle (1957) suggested that the pancreatitis may be the primary lesion. The associated hypocalcaemia in acute pancreatitis may give rise to hyperfunction of the parathyroids resulting in hyperplasia or adenoma. Dent (1962) supported the hypothesis that hyperparathyroidism is secondary to the steatorrhoea and hypocalcaemia in cases of pancreatitis, the parathyroid glands being thereby stimulated and becoming autonomous.

This idea is supported by Paloyan and Paloyan (1967) who state that recurrent pancreatitis possibly antedates and induces the development of secondary hyperparathyroidism in the syndrome where the two diseases co-exist. In addition to these authors, Avioli et al. (1969) showed that (a) hypocalcaemia could be induced in dogs by glucagon if the animals had an intact thyroid gland but not if they were thyroidectomized, and (b) in situ perfusion of the thyroid with glucagon led to a rapid fall in systemic calcium levels and the liberation of a biologically active substance into the thyroid venous effluent which induced hypocalcaemia in intact rats. This suggests that the glucagon-induced hypocalcaemia气 observed in dogs results from release of a calcitonin- $\bar{Z}$ like substance. Therefore pancreatitis in man may beQ associated with increased glucagon secretion giving.. hypocalcaemia by inhibiting bone resorption directly $\overrightarrow{\vec{F}}$ or by stimulating the thyroid to release calcitonin $\frac{\vec{f}}{\sigma}$ This may subsequently stimulate compensatory등 release of parathyroid hormone to maintain calcium $\bar{\omega}$. homeostasis resulting in secondary hyperparathy- $\widehat{\nabla}$ roidism. Hyperglucagonaemia was discovered in eight out of nine patients with hyperparathyroidismos (Paloyan, Paloyan and Harper, 1967). It was attri- $\overrightarrow{0}$ buted to either an alpha cell hyperplasia that occurswith chronic pancreatitis or as a compensatory $\vec{\sigma}^{\circ}$ mechanism to counteract parathyroid hormone.

Ballon et al. (1972) described a case in which a parathyroid adenoma was incriminated as causing severe relapsing pancreatitis in a persistently? normocalcaemic patient. The mechanism for the causation of the pancreatitis was obscure in the face ${ }_{i}^{+}$ of persistent normocalcaemia and they observedor that the coincidental association of diseases musto be considered. The association of hypercalcaemia or pancreatic calcification and pancreatitis should ${ }_{\mathbb{\Phi}}^{\top}$ direct attention to studies diagnostic of hyperparathyroidism. Indeed, in acute fulminating pancreatitis, Bockus (1950) points out that if the blood calcium is not depressed after the first 2 days, hyperpan- $\overrightarrow{-}$ thyroidism should be suspected.

An increased awareness of this association ma reward the clinician in his care of patients with pancreatitis by the discovery of hyperparathy- $\frac{\partial}{0}$ roidism. It also alerts the physician treating hyper-® parathyroidism that pancreatitis may be a sudden $\stackrel{\Phi}{\varrho}$ and dangerous complication. As parathyroidectomy $\vec{\Rightarrow}$ will greatly lessen the chance of further attacks of $\frac{0}{3}$ pancreatitis, it is vital that this association be recognized and it is suggested that all patients with pancreatitis are fully investigated to exclude hyperparathyroidism. The fact that removal of a para- $\frac{3}{3}$. thyroid tumour heals a relapsing pancreatitis is good:proof of a pathogenetic connection of the two 3 . diseases.

\section{Acknowledgments}

I wish to thank Mr C. F. Critchley for permission to publish case 1 , Professor $\mathrm{H}$. Ellis for case 2 and $\mathrm{Mr}$ T. Moore for case 3. Also my wife, Mrs K. Cruickshank and $\operatorname{Dr} \stackrel{N}{N}$ Angela Fairney for their help in the preparation of this paper.

\section{Addendum}

Two further cases have been seen with clinical pancreatitis and proved hyperparathyroidism during the last ten months by the author at St Helier Hospital. Unfortunately, the $\mathbb{D}$ pancreatitis was not proved biochemically in either case, ${ }^{-}$ but no further attacks have occurred since the removal of $\square$ parathyroid adenomas. 
In addition a further female patient with acute pancreatitis, proved biochemically, was seen, in June 1975 at Kingston Hospital, who maintained a high serum calcium during the pancreatitis. A $2 \cdot 8 \mathrm{~g}$ upper right parathyroid adenoma was excised with great improvement and no further attacks of pancreatitis.

\section{References}

Aldis, A.S. (1961) Clinical experiences of the lesser known manifestations of hyperparathyroidism. Proceedings of the Royal Society of Medicine, 54, 489.

ANGLEM, T.J. (1966) Acute hyperparathyroidism: A surgical emergency. Surgical Clinics of North America, 46, 727.

Avioli, L.V., Birge, S.J., Scott, S. \& Shieber, W. (1969) Role of the thyroid gland during glucagon-induced hypocalcemia in the dog. American Journal of Physiology, 216, 939.

Ballon, S., Cohen, H. \& Strasberg, Z. (1972) Recurrent pancreatitis due to parathyroid adenoma in a normocalcaemia patient. Canadian Medical Association Journal 106, 51 .

Battersby, C., Burnett, W. \& Winch, J. (1969) Pancreatitis associated with hyperparathyroidism. Medical Journal of Australia, 2, 1268.

BockUS, H.L. (1950) Recent experience in the diagnosis and treatment of acute pancreatitis. In: Postgraduate Gastroenterology, W.B. Saunders, Philadelphia.

Bockus, H.L. (1969) Acute Pancreatitis. In: Maingot's Abdominal Operations (5th edition), Appleton-CenturyCrofts, New York.

Cope, O., Cullver, P.J., Mixter, C.G. \& Nardi, C.A. (1957) Pancreatitis, a diagnostic clue to hyperparathyroidism. Annals of Surgery, 145, 857.

DAwson, J.W. \& Struthers, J.W. (1923) Generalized osteitis fibrosa cystica with parathyroid tumour and metastatic calcification, including a critical discussion of pathological processes underlying osseous dystrophies. Edinburgh Medical Journal, 30, 421.

DENT, C.E. (1962) Some problems of hyperparathyroidism. British Medical Journal, 2, 1419; 1495.

ERDHEIM, J. (1903) Zur normalen und pathologischen Histologie der Glandule thyroidea, parathyroidea und Hypophysis. Beiträge zur pathologischen Anatomie und zur allgemeinen Pathologie, 33, 158.

FINK, W.J. \& FinROCK, J.D.( 1961) Fatal hyperparathyroid crisis associated with pancreatitis. American Surgeon, 27, 424.

Green, N.A. (1972) Personal communication.

Haverback, B.J., Dyce, B., Bundy, H. \& Edmonson, H.A. (1960) Trypsin, trypsinogen and trypsin inhibitor in human pancreatic juice. Mechanism for pancreatitis associated with hyperparathyroidism. Annual Journal of Medicine, 29, 424

HenRiksson, C. (1960) Acute hyperparathyroidism and acute pancreatitis. Acta pathologica et microbiologica scandinavica, 50, 42.

HoAR, C.S., JR. \& GoRlin, R. (1958) Hyperparathyroidism and acute pancreatitis. New England Journal of Medicine, 258, 1052.

Howat, H.T. (1972) Personal communication.

HUEPER, W. (1927) Metastatic calcifications in the organs of the dog after injections of parathyroid extract. Archives of Pathology, 3, 14.

JACKSON, C.E. (1958) Hereditary hyperparathyroidism associated with recurrent pancreatitis. Annals of Internal Medicine, 48, 829.

JAWAHEER, S. (1963) Primary hyperparathyroidism, acute urinary infections and pancreatitis. British Medical Journal, $1,450$.

KeLLY, T.R. (1968) Relationship of hyperparathyroidism to pancreatitis. Archives of Surgery, 97, 267.
Kelly, T.R. \& FALOR, W.H. (1968) Hyperparathyroid crisis associated with pancreatitis. Annals of Surgery, 168, 917.

KeYNES, W.M. (1962) Pancreatitis and hyperparathyroidism. Lancet, i, 859.

Leeson, P.M. \& Fourman, P. (1966) Acute pancreatitis from vitamin $D$ poisoning in a patient with parathyroid deficiency. Lancet, i, 1185.

Lejeune, E., Lambert, R., Queneau, P., Phelip, E., Daly, J.P. \& Quelin, P. (1972) Pancréatite révélatrice d'une hyperparathyroïdie. Journal de Médecine de Lyon, 53, 763.

Martin, L. \& ConseKA, J.D. (1947) Pancreatic calculosis. Journal of the American Medical Association, 135, 1055.

McGeown, M.G. (1973) Personal communication.

Meltzer, L.E., Palmon, F.R., JR., Paik, Y.K. \& Custur, R.P. (1962) Acute pancreatitis secondary to hypercalcaemia of multiple myeloma. Annals of Internal Medicine, 57, 1008.

Mixter, C.G., JR, Keynes, M. \& Cope, O. (1962) Further experience with pancreatitis as a diagnostic clue to hyperparathyroidism. New England Journal of Medicine, 266, 265.

Morrison, E. (1973) Personal communication.

Oliver, W.A. (1939) Acute hyperparathryoidism, Lancet, ii, 240.

ORY, E.M., HiSEY, D.P. \& REDMOND, D.E., JR (1970) Acute pancreatitis, hypercalcaemia, hyperuricaemia and hypertension secondary to parathyroid adenoma. Southern Medical Journal, 63, 194.

Page, F. (1954) Diagnostic Problems No. 14. A case of nalignant melanoma, steatorrhoea, Paget's disease and hyperparathyroidism. Archives of the Middlesex Hospital. 4, 215.

Paloyan, E. \& Paloyan, D. (1967) Alpha cell hyperplasia in calcific pancreatitis associated with hyperparathyroidism. Journal of the American Association, 200, 757.

Paloyan, E., Paloyan, D. \& Harper, P.V. (1967) The role of glucagon hypersecretion in the relationship of pancreatitis and hyperparathyroidism. Surgery, 62, 167.

Plough, I.D. \& Kyle, L.H. (1957) Pancreatic insufficiency and hyperparathyroidism. Annals of Internal Medicine, 47, 590.

Pyrah, L.N., Hodgkinson, A. \& Anderson, C.K. (1966) Primary hyperparathyroidism. British Journal of Surgery, 53, 245.

Rogers, H.M. (1946) Parathyroid adenoma and hypertrophy of the parathyroid galnds. Journal of the American Medical Association, 130, 22.

Rogers, H.M., Keatings, F.R., Morlock, C.G. \& Barker, N.W. (1947) Primary hypertrophy and hyperplasia of parathyroid glands associated with duodenal ulcer; report of an additional case with special reference to metabolic, gastrointestinal and vascular changes. Archives of Internal Medicine, 79, 307.

SchmidT, H. \& Creutzfeldt, W. (1970) Calciphylactic pancreatitis and pancreatitis in hyperparathyroidism. Clinical Orthopaedics, 69, 135.

SINCLAIR, I.S.R. (1956) Observations on a case of external pancreatic fistula in man. Brtiish Journal of Surgery, 44, 250.

Sмith, F.B. \& Cooke, R.T. (1940) Acute fatal hyperparathyroidism. Lancet, ii, 650.

Steyn, J.H., Duncan, T. \& Logie, N.G. (1966) The association of pancreatitis and hyperparathyroidism. British Journal of Surgery, 53, 778.

TAYLOR, G.W. (1972) Personal communication.

TRAPNELL, J.E. (1966) The natural history and prognosis of acute pancreatitis. Annals of the Royal College of Surgeons of England, 38, 265.

Turchi, J.J., Flandreau, R.H., Forte, A.L., French, G.N. \& LuDwIG, G.D. (1962) Hyperparathyroidism and pancreatitis. Journal of the American Medical Association, 180, 799.

Watson, L. (1972) Personal communication. 